\title{
In Vitro Growth and Regeneration of Drosera spatulata Labill. on Various Media
}

\author{
Mirna Curkovic Perica ${ }^{1}$ \\ Tobacco Institute Zagreb, Planinska 1, 10000 Zagreb, Croatia
}

Jasna Berljak

University of Zagreb, Faculty of Science, Department of Molecular Biology, Rooseveltov trg 6, 10001 Zagreb, Croatia

Additional index words. sundew, tissue culture, propagation, flowering, $\mathrm{pH}$

\begin{abstract}
Conditions for in vitro multiplication and flowering of Drosera spatulata plants were established. Shoot tips of greenhouse-grown plants were sterilized with $1 \%$ or $0.5 \%$ sodium hypochlorite. The influence of different media concentrations, hormone supplementation, and pH was investigated. Full MS medium without growth regulators was the best for regeneration and multiplication of plants. Regenerated shoots rooted spontaneously on medium without growth regulators and without transfer to additional medium. In 3 months, 100 to 200 plants were generated per explant. Flowering was induced on media supplemented with plant growth regulators. Plants were acclimatized on sterile peat.
\end{abstract}

Plumbagin, a phytochemical produced by the carnivorous genus Drosera (Bonnet et al., 1984b; Crouch et al., 1990; Gupta et al., 1993), is extracted for pharmaceutical preparations because of its antispasmatic and antibiotic activity (Didry et al., 1986; Wurm et al., 1984) If carnivorous plants are to be used for investigations or extractions of useful chemicals, many plants must be available. Since their natural populations are scarce, in vitro propagation would be useful. Until now, the following species of genus Drosera have been successfully cultured in vitro: D. binata $\mathrm{La}$ Billardiere (Anthony, 1992; Caniato et al., 1989), D. capensis L. (Anthony, 1992; Caniato et al., 1989; Crouch et al., 1990), D. natalensis Diels (Crouch and Van Staden, 1988; Crouch et al., 1990; Finnie and Van Staden, 1993), Drosera-regia Stephens (Janssens, 1986), D. rotundifolia L. (Anthony, 1992; Bonnet et al., 1984a; Kukulczanka and Czastka, 1987; Simola, 1978), and D. spatulata Labill. (Blehova et al., 1990, 1992). However, a completely defined medium for $D$. spatulata (the sundew) has not been developed and seeds have been the only material successfully sterilized for primary culture establishment. Consequently, investigations were conducted to determine the most suitable, fully defined medium for rapid propagation and flowering.

Received for publication 12 June 1995. Accepted for publication 11 May 1996. The cost of publishing this paper was defrayed in part by the payment of page charges. Under postal regulations, this paper therefore must be hereby marked advertisement solely to indicate this fact.

${ }^{1}$ Current address: Institute of Microbiology, Univ. of Graz, Universitätsplatz 2, A- 8010 Graz, Austria.

\section{Materials and Methods}

Shoottips, 4 to $6 \mathrm{mmlong}$, of well-developed, greenhouse-grown $D$. spatulata $(>2.5 \mathrm{~cm}$ in diameter) were used as initial explants. Roots and lower leaves were cut off and shoot apices were sterilized with either $70 \%$ ethanol (5 sec), $3 \%$ sodium hypochlorite $(\mathrm{SH})$ from Izosan G (Pliva, Zagreb) (5 min); $70 \%$ ethanol (5 $\mathrm{sec}), 2 \% \mathrm{SH}(5 \mathrm{~min}) ; 1.5 \% \mathrm{SH}(5 \mathrm{~min}) ; 1 \% \mathrm{SH}$ (5 min); $0.5 \% \mathrm{SH}(7 \mathrm{~min}) ; 6 \% \mathrm{H}_{2} \mathrm{O}_{2}(15 \mathrm{~min})$; $3 \% \mathrm{H}_{2} \mathrm{O}_{2}(20 \mathrm{~min})$. All of the methods used were followed by three 3 -min washes in sterile distilled water.

Explants were inoculated separately on full-strength MS medium (Murashige and Skoog, 1962) supplemented with sucrose (30 $\left.\mathrm{g} \cdot \mathrm{L}^{-1}\right)$ and agar $\left(8 \mathrm{~g} \cdot \mathrm{L}^{-1}\right)$ (Biolife, Milano), in glass culture tubes $(30 \times 120 \mathrm{~mm})$ containing $10 \mathrm{~mL}$ of medium. Medium was adjusted to pH 5.7 with $\mathrm{NaOH}$ before autoclaving. After 4 months in culture, plants were subcultured on full-strength MS medium and 3/4, 1/2, 1/4, $1 / 8$ macro salts dilutions of the medium supplemented as noted, or on B medium (Boxus, 1974) and its $1 / 2,1 / 4$, and $1 / 8$ macro salts dilutions supplemented with glucose (40 $\left.\mathrm{g} \cdot \mathrm{L}^{-1}\right)$ and agar $\left(8 \mathrm{~g} \cdot \mathrm{L}^{-1}\right)$. In this experiment, in vitro-derived single leaves, 12 to $14 \mathrm{~mm}$ long, also were inoculated. In all other experiments, whole plants ( $\approx 8$ to $15 \mathrm{~mm}$ in diameter) were used for subculturing. Each experiment had 24 replicate cultures per treatment and every experiment was conducted twice. All cultures were maintained at $24 \pm 4{ }^{\circ} \mathrm{C}$ under a 16 -h photoperiod of cool-white light (40 $\mu \mathrm{mol} \cdot \mathrm{m}^{-2} \cdot \mathrm{s}^{-1}$ ).

Effects of growth regulators also were investigated. 1/4 MS medium was supplemented with (in $\mu \mathrm{M}$ ): indole-3-butyric acid (IBA) (1.97, 4.9,9.8); indole-3-acetic acid (IAA) (5.7) plus kinetin (K) (9.3); IAA (22.8) plus K (9.3); $\alpha$ naphthaleneacetic acid (NAA) $(0.54$ or 5.4$)$ plus K(9.3); IAA (0.143) plus 6-benzylaminopurine (BA) (0.44); IBA (0.12) plus BA (0.44); NAA (0.13) plus BA (0.44); IAA (0.143) plus $\mathrm{K}$ (0.46); IBA (0.12) plus K (0.46); NAA (0.13) plus K (0.46). B medium was supplemented with (in $\mu \mathrm{M})$ : IBA (4.9), BA (4.44) plus IBA (4.9).

To estimate the influence of $\mathrm{pH}$ on plant growth, whole plants were transferred from $1 / 4 \mathrm{MS}$ (pH 5.7) to $1 / 4 \mathrm{MS}$ medium, adjusted to $\mathrm{pH}$ values of $4.0,5.0,6.0$, and 7.0 , before autoclaving. Average size of plants was estimated 8 weeks after inoculation.

Twenty plants grown on full-strength and 20 grown on each diluted MS medium were acclimatized on sterile peat in plastic containers $(6.5 \mathrm{~cm}$ in diameter) enclosed in vented plastic bags. After $18 \pm 2$ days of growth in a temperature-controlled room at $24 \pm 4^{\circ} \mathrm{C}$ and a 16-h photoperiod of cool-white light (40 $\mu \mathrm{mol} \cdot \mathrm{m}^{-2} \cdot \mathrm{s}^{-1}$ ), plastic bags were gradually removed. Plants were transferred to a greenhouse and surviving plants were counted 2 months after transfer to ex vitro conditions.

Mean values and standard deviations were used for analysis and interpretation of the results.

\section{Results and Discussion}

The main problem with establishment of carnivorous plants in vitro is effective sterilization of explants (Anthony, 1992). In our experiment, shoot tips disinfected with $1 \%$ or $0.5 \%$ SH yielded $20 \%$ and $10 \%$ sterile explants, respectively. Ethanol used in combination with $2 \%$ or $3 \% \mathrm{SH}$ or $1.5 \% \mathrm{SH}$ alone caused all explants to turn brown and decay. Sterilization with $\mathrm{H}_{2} \mathrm{O}_{2}$ was unsuccessful.

Presumably, sterile explants were inoculated separately on full-strength, hormonefree MS medium, and after 4 months in culture each tube contained 200 to 300 plantlets. Plants and single leaves derived from that primary culture were subcultured on full-strength and diluted MS and B media. Regeneration of plants was high on both tested media (Table 1 ). When single leaves were subcultured, regeneration occurred 2 weeks after that on whole plants, but was high $(83 \%$ to $100 \%)$ nevertheless.

MS medium proved to be more suitable for D. spatulata growth than B medium. Multiplication of plants decreased with diluting the medium (Table 1). This result was unexpected, since carnivorous plants normally grow in nutrient-poor areas (Juniper et al., 1989), and experimental work on the genus Drosera shows that these plants readily and even more successfully grow on diluted culture media (Anthony, 1992; Crouch and Van Staden, 1988; Jannssens, 1986; Kukulczanka and Czastka, 1988; Simola, 1969).

Addition of growth regulators in the combinations and concentrations used by us retarded plant growth and multiplication rate. When NAA was used alone or in combination with other growth regulators, shoots formed multiple and extremely thick roots and only $50 \%$ of the plants had regenerated shoots 6 weeks after subculturing. In contrast, plants 
Table 1. Effect of medium (hormone-free) and strength on regeneration and multiplication of Drosera spatulata plants 6 weeks after subculturing of whole plants.

\begin{tabular}{lrc}
\hline $\begin{array}{l}\text { Medium } \\
\text { and strength }\end{array}$ & $\begin{array}{c}\text { Regeneration } \\
(\%)\end{array}$ & $\begin{array}{c}\text { Plants/tube } \\
\text { (mean values } \pm \text { SD) }\end{array}$ \\
\hline MS & 100 & $43.0 \pm 2.1$ \\
Full & 92 & $40.8 \pm 3.2$ \\
$3 / 4$ & 100 & $39.0 \pm 2.4$ \\
$1 / 2$ & 100 & $37.7 \pm 2.6$ \\
$1 / 4$ & 83 & $35.2 \pm 3.3$ \\
$1 / 8$ & & \\
B & 92 & $17.2 \pm 1.5$ \\
Full & 100 & $14.2 \pm 2.7$ \\
$1 / 2$ & 100 & $12.2 \pm 2.4$ \\
$1 / 4$ & 83 & $10.8 \pm 2.1$ \\
$1 / 8$ & & \\
\hline
\end{tabular}

${ }^{\mathrm{z}} \mathrm{MS}=$ Murashige and Skoog medium; $\mathrm{B}=$ Boxus medium.

subcultured on MS medium without growth regulators usually produced adventitious shoots before root development.

In vitro-produced plants flowered in the following media: $100 \%$ on $1 / 4 \mathrm{MS}$ with 0.12 $\mu \mathrm{M}$ IBA plus $0.44 \mu \mathrm{M}$ BA; $67 \%$ on $1 / 4 \mathrm{MS}$ with $0.143 \mu \mathrm{M}$ IAA plus $0.44 \mu \mathrm{M}$ BA; $50 \%$ on $1 / 4$ MS with $0.143 \mu \mathrm{M}$ IAA plus $0.46 \mu \mathrm{M} \mathrm{K}$; and $50 \%$ on B medium supplemented with $4.9 \mu \mathrm{M}$ IBA plus $4.44 \mu \mathrm{M}$ BA. Although Drosera species spontaneously flower under in vitro conditions, the results of our experiments show that it is possible to control time of flowering with growth regulators, which permits having flowering plants in various periods of the year, thus allowing investigation of related biochemical, physiological, and other properties.

Plant growth was strongly affected by medium $\mathrm{pH}$. Plants inoculated on 1/4 MS medium adjusted to $\mathrm{pH} 4$ had the biggest average diameter $(3 \mathrm{~cm})$. Average diameter of plants grown on the medium adjusted to $\mathrm{pH} 5$, $\mathrm{pH} 6$, and $\mathrm{pH} 7$ was $2.3,2.2$, and $2.1 \mathrm{~cm}$, respectively. However, since sundews grow on acidic soils (Juniper et al., 1989), we expected that growth would be better under low $\mathrm{pH}$.

Plants grown on full-strength and diluted MS media were acclimatized, and after 2 months of growth ex vitro, $80 \%$ of plants survived. Media dilution had no effect on plant survival.

Growth and multiplication of D. spatulata was possible on all media tested. In our experiments, we found that MS medium without growth regulators was the best for regeneration and multiplication of plants. It was not necessary to use the usual three-stage system for shoot induction, multiplication, and rooting, respectively. Shoots rooted spontaneously on medium without growth regulators and without transfer to additional medium.

The main problem with Drosera tissue culture is sterilization of plant material. Even in subcultures, contamination was not completely eliminated, probably due to the symbiotic microorganisms in plants (Anthony, 1992). We managed to apparently sterilize shoot tips of D. spatulata and establish optimal conditions for rapid multiplication and flowering of this species. Although most of the plant material is lost during sterilization, this is negligible in comparison to the number of plantlets that could be generated in culture in the short time. In our experiments, we obtained 100 to 200 regenerated plantlets from a single explant (plant or leaf) in 3 months.

\section{Literature Cited}

Anthony, J.L. 1992. In vitro propagation of Drosera spp. HortScience 27:850.

Blehova, A., K. Erdelsky, and M. Bobak. 1992. Cultivation of organ and callus culture of Drosera spatulata Labill. in in vitro conditions. Acta Facultatis Rerum Naturalium Universitas Comenianae Physiol. Plant. 28:93-102.

Blehova, A., V. Somsakova, and M. Bobak. 1990. Anatomical studies of the development of new plants from the leaves of the sundew (Drosera spatulata L.) in in vitro conditions. Acta Facultatis Rerum Naturalium Universitas Comenianae Physiol. Plant. 24:33-42.

Bonnet, M., M. Coumans, J.L. Ramaut, and T. Gaspar. 1984a. Vegetative multiplication in vitro of the sundew Drosera rotundifolia. Archives Internationales de Physiologie et de Biochimie Physiol. Biochim. 92:16-17.
Bonnet, M., M. Coumans, M. Hofinger, J.L. Ramaut, and T. Gaspar. 1984b. High performance gas chromatography of 1,4-naphtoquinones from Droseraceae. Chromatographia 18:621-622.

Boxus, P.H. 1974. The production of strawberry plants by in vitro micropropagation. J. Hort. Sci. 49:209-210.

Caniato, R., R. Filippini, and E.M. Cappelletti. 1989. Naphtoquinone contents of cultivated Drosera species Drosera binata, Drosera binata var. Dichotoma and Drosera capensis. Intl. J. Crude Drug Res. 27:129-136.

Crouch, I.J., J.F. Finnie, and J. Van Staden. 1990. Studies on the isolation of plumbagin from in vitro and in vivo grown Drosera species. Plant Cell Tissue Organ Cult. 21:79-82.

Crouch, I.J. and J. Van Staden. 1988. In vitro propagation of Drosera natalensis. S. Afr. J. Bot. 54:94-96.

Didry, N., M. Pinkas, and L. Dubrenil. 1986. Activite antibacterienne de naphthoquinones d'originale vegetale. Ann. Pharmaceutiques Francaises 44:73-78.

Finnie, J.F. and J. Van Staden. 1993. Drosera spp. (Sundew): Micropropagation and in vitro production of plumbagin, p. 164-177. In: Y.P.S. Bajaj (ed.). Biotechnology in agriculture and forestry, vol. 24. Medicinal and aromatic plants V. Springer-Verlag, Berlin.

Gupta, M.M., R.K. Verma, G.C. Uniyal, and S.P. Jain. 1993. Determination of plumbagin by normal-phase high-performance liquid chromatography. J. Chromatography 637:209-212.

Janssens, J. 1986. In vitro propagation of Sundew Drosera-regia Stephens. Meded Fac Landbouwwet. Rijksuniv. Gent 51:61-66.

Juniper, B.E., R.J. Robins, and D.M. Joel. 1989. The carnivorous plants. Academic, San Diego.

Kukulczanka, K. and B. Czastka. 1987. Propagation of Drosera L. in vitro. Wiad Bot. 31:61-64.

Murashige, T. and F. Skoog. 1962. A revised medium for rapid growth and bioassay with tobacco tissue cultures. Physiol. Plant. 15:473497.

Simola, L.K. 1978. Dipeptides as nitrogen sources for Drosera rotundifolia in aseptic culture. Physiol. Plant. 44:315-318.

Wurm, D.L., H. Grimm, U. Geres, and H. Schmidt. 1984. Plumbagin: Reactivität, Toxizität und antimikrobielle Aktivität des Drosera und Plumbago Arten vorkommenden Naturstoffe. Deutsche Apotheker Zeitung 124:2128-2132. 